\title{
Glycemic Index of Sugars Extracted from Immature Coconut Water: Case of Coconut Palms (Cocos nucifera L.) WAT, MYD and PB121+
}

\author{
Akpro Lathro Anselme1, Gbogouri Grodji Albarin', Konan Konan Jean-Louis ${ }^{2}$, \\ Gbakayoro Jean Brice ${ }^{1}$, Nemlin Gnopo Jean ${ }^{3}$
}

\author{
${ }^{1}$ Laboratory of Nutrition and Food Safety, UFR-STA, University Nangui Abrogoua, Abidjan, \\ Côte d'Ivoire \\ ${ }^{2}$ Laboratory of Technology and Oil Analyse, Research Station Marc Delorme, CNRA, \\ Abidjan, Côte d'Ivoire \\ ${ }^{3}$ Technological Research Station of Bingerville, CNRA, Abidjan, Côte d'Ivoire \\ Email: lathroas@yahoo.fr
}

How to cite this paper: Anselme, A.L., Albarin, G.G., Jean-Louis, K.K., Brice, G.J. and Jean, N.G. (2018) Glycemic Index of Sugars Extracted from Immature Coconut Water: Case of Coconut Palms (Cocos nucifera L.) WAT, MYD and $\mathrm{PB} 121^{+}$. Journal of Biosciences and Medicines, 6, 99-110.

https://doi.org/10.4236/jbm.2018.68008

Received: July 25, 2018

Accepted: August 27, 2018

Published: August 30, 2018

Copyright $\odot 2018$ by authors and Scientific Research Publishing Inc. This work is licensed under the Creative Commons Attribution-NonCommercial International License (CC BY-NC 4.0). http://creativecommons.org/licenses/by-nc/4.0/ (c) (i) (8) Open Access

\begin{abstract}
In order to do a best stipulation on her consumption, it is necessary to know if a food provoke faintly, fairly or highly the glyceamia. The aim of this work was to evaluate the glycemic index of coconut water sugar from three coconuts varieties. So, with a cohort of 15 people, a capillary blood was collect after sugar ingestion and the glycaemia read directly on a glucometer. The result showed that the brown and white sugar from coconut sugar can be classified as low glycemic index food. Also, the glycemic indexes of white coconut water sugar are 2 to 3 more lower than that the brown sugar. The glycemic indexes of sugars vary according to the variety of coconut used. The sugars of the coconut palm (MYD) are more hyperglycemic than those of the hybrid $\left(\mathrm{PB} 121^{+}\right)$which is more hyperglycemic than the sugars of the coconut palm (WAT). Thus, with a controlled consumption, the coconut water sugars could be the sugars that are best for the health of the healthy and diabetic populations because it raises slightly the postprandial glucose.
\end{abstract}

\section{Keywords}

Glycemic Index, Brown Sugar, White Sugar, Coconut Water Sugar, Glycemic Response 


\section{Introduction}

The Diabetes is a glucose metabolism disorder that occurs frequently in Western countries, but is quite common nowadays in African countries. In fact, diabetes is characterized by a high level of glucose in the blood. There are two types of diabete: the Type 1 diabetes that is linked to a viral infection, a toxin or an autoimmune reaction, and the Type 2 diabetes that is favored by a hereditary predisposition, a diet rich in sweet products, refined and poor in whole grains [1]. There is also gestational diabetes that happens during the 9 months of pregnancy and other diabetes (diabetes maudy...). This disease causes some complications that can be avoided by a medical care, a balanced diet and regular sports activity in addition to a prescription drug [2] [3] [4]. Adequate dietary treatment should be followed by patients with diabetes added to regular control of glucose level in their blood. Moreover, diabetic people must pay attention to their food, and adopt a correct style life [5]. For this reason, sugar is often forbidden to them because they are empty calories which pass quickly in the blood and increasing the glucose level. Sugar is composed by single monosaccharide or disaccharide element, example of sucrose, fructose syrup etc. The most daily dietary recommendations are going to the foods that contain low glycemic index, not only for people with obesity or diabetes, but also for the general public [6]. The glycemic index of a food is conditioned by its composition in fiber, simple sugars, polyphenol etc. However, studies conducted on the sugar of coconut water has shown that this sugar is crude and contains, unlike other sugars, fibers, proteins, lipids, minerals, polyphenols, flavonoids with considerable power antioxidant [7], which are regulating factors of postprandial glucose. It appears appropriate to conduct a study on glycemic index of this sugar for use in dietary prescriptions for people at risk of diabetes. The objective of this study is therefore to determine the sugar glycemic index of coconut water from immature coconuts.

\section{Material and Methods}

\subsection{Population of Study}

This investigation involved 15 young adults volunteers, aged 18 to 39 , apparently in good health, recruited from Nangui Abrogoua University following a call for applications. The choice of this population was based on criteria related to biological parameters (blood glucose and hypertension) and morpho-anthropometric (weight, height and IMC) and a family history of diabetes, obesity and hypertension. The object of these preliminaries was to reassure oneself about the good health of the study population. The pregnant and lactating women were excluded from this test. The consent participants were informed to the study protocol was, that was explained to theme. The subjects totally agree for this test, were submitted to 12 hours of fasting before the beginning of the sessions covering the study. 


\subsection{Biological Material}

Biological material was consisted of two types of test sugars (red sugars and white sugar) extracted from the water of coconut nuts WAT (West African Tall), MYD (Malaysian Yellow Dwarf) and PB121 (Port-Bouet 121 improved) and control sugar (Anhydrous Glucose, Cooper, France). The choices of these cultivars were guided by the following: WAT is the most common coconut cultivar in the West African zone. It remains traditionally the most popular ecotype in most peasant plantations and also serves as a witness to the characterization of accessions of tall coconut trees. The NJM is a dwarf ecotype of great utility in several genetic cross-breeding experiments when creating Dwarf $\times$ Tall or Dwarf $\times$ Dwarf hybrid varieties. The $\mathrm{PB} 121^{+}$is very popular around the world for their high early production. This will help to assess the sugar behavior of each ecotype on people's blood sugar levels.

\subsection{Methods}

Reference food: Anhydrous glucose has been used as a reference food [8]. This anhydrous glucose used is produced by the Cooper laboratory in France.

Tested food: The brown and white sugars of the immature nut water of three coconut varieties (WAT, MYD, PB121 $1^{+}$) were the six (6) foods tested in this study. White and brown sugars were respectively obtained by cold and heat according to the work of Lathro [7].

Amount of sugar (extracted of coconut water) to consume: According to the reference food (anhydrous glucose), the amount of food to be tested contained $50 \mathrm{~g}$ of available carbohydrates. Thus, based on total carbohydrate levels, available carbohydrates for sugars were calculated by differentiating total carbohydrates from total raw fiber based on the following equation:

$$
\text { Availables Glucids }(\mathrm{g})=\text { Total Glucids }(\mathrm{g}) \text { - Fiber }(\mathrm{g})
$$

The amount of coconut water sugar required to obtain $50 \mathrm{~g}$ of available carbohydrates was determined according to the following equation:

$$
\text { Food portion to introduce }(\mathrm{g})=(100 / X) \times Y
$$

$X$ : quantity of carbohydrates available in $\mathrm{g} / 100 \mathrm{~g}$ of tested food (coconut water sugars).

$Y$ : amount of available carbohydrates that the tested food is required to provide.

From the contents of fibers and total carbohydrates and available carbohydrates, the portions of the various sugars to be ingested by the subjects were calculated using Equation (2) and then recorded in Table 1. The contents of fibres were evaluated according Wende Wolf (1968) method using the sulphuric acid (0.25 N) and sodium hydroxide $(0.31 \mathrm{~N})$ to carry out respectively $30 \mathrm{~min}$ ebulition foreach reagent. The residu obtained after filtration was dried and incinerated. 
Table 1. Amount of coconut water sugar to consume by each subject (panelist).

\begin{tabular}{ccccc}
\hline Foods (sugars) & $\begin{array}{c}\text { Total glucids } \\
(\mathrm{g} / 100 \mathrm{~g})\end{array}$ & $\begin{array}{c}\text { Fibers } \\
(\mathrm{g} / 100 \mathrm{~g})\end{array}$ & $\begin{array}{c}\text { Availables glucids } \\
(\mathrm{g} / 100 \mathrm{~g})\end{array}$ & $\begin{array}{c}\text { Amount sugar } \\
\text { to consume }(\mathrm{g})\end{array}$ \\
\hline MYD-Brown & $78.40^{\mathrm{a}}$ & $2.47^{\mathrm{d}}$ & $75.93^{\mathrm{g}}$ & $65.85^{\mathrm{a}}$ \\
MYD-White & $86.23^{\mathrm{b}}$ & $2.27^{\mathrm{d}}$ & $83.96^{\mathrm{f}}$ & $59.55^{\mathrm{c}}$ \\
PB121+-Brown & $87.03^{\mathrm{b}}$ & $2.03^{\mathrm{d}}$ & $85.00^{\mathrm{f}}$ & $58.82^{\mathrm{c}}$ \\
PB121+-White & $78.12^{\mathrm{a}}$ & $2.29^{\mathrm{d}}$ & $76.51^{\mathrm{g}}$ & $65.65^{\mathrm{a}}$ \\
WAT-Brown & $81.18^{\mathrm{a}}$ & $1.79^{\mathrm{f}}$ & $79.39^{\mathrm{g}}$ & $62.98^{\mathrm{t}}$ \\
WAT-White & $86.26^{\mathrm{b}}$ & $1.58^{\mathrm{f}}$ & $84.68^{\mathrm{f}}$ & $59.04^{\mathrm{c}}$ \\
\hline
\end{tabular}

MYD: Malaysia Yelow Dwarf, WAT: West African Tall, PB121 ${ }^{+}$: Port-Bouët 121 improved. The table is read in columns. Thus, in the same column, averages with different superscript lowercase letters indicate the existence of a significant difference between sugars for this variable. The lack of difference is indicated by identical letters.

\subsubsection{Glycemic Response of Coconut Water Sugars}

\section{1) Principle}

The principle of measuring the glycemic index (GI) is based on oral hyperglycemia with the reference food ( $50 \mathrm{~g}$ of anhydrous glucose) and on a postprandial glycemic response of the foods to be tested (brown and white sugars of nuts water from WAT, MYD and $\mathrm{PB} 121^{+}$), and monitoring blood glucose for $120 \mathrm{mi}-$ nutes [9].

\section{2) Methodology}

The subject (panelist) started the test by taking his fasting blood glucose, corresponding to the blood sugar at $\mathrm{t}_{0}(\mathrm{GAJ}), 5$ minutes after his arrival. Indeed, the subjects were submitted to 12 hours of fasting, took their last meals at 20 hours maximum the day before to start the test at 8 o'clock and should not practice any unusual sport on the day of the test. Also, only one food was tested per day so 7 days were needed for this study which took into account 6 different sugars in addition to anhydrous glucose. After taking fasting blood glucose from each subject, each of them consumed the reference food (50 $\mathrm{g}$ of anhydrous glucose) dissolved delicately in $250 \mathrm{~mL}$ of mineral water. The duration of consumption was 3 to 4 minutes. Postprandial glucose was determined over 2 hours, each 15 min during the 1st hour and then every 30 minutes during the 2 nd hour (0 min, $15 \mathrm{~min}, 30 \mathrm{~min}, 45 \mathrm{~min}, 60 \mathrm{~min}, 90 \mathrm{~min}$ and $120 \mathrm{~min}$ ). In practice, capillary blood (approximately $0.6 \mu \mathrm{L}$ ) was collected at the fingertips using a lancing lancet (BD Microtainer, Contact-Activated Lancet, Poland, USA) measuring $2.0 \mathrm{~mm} \times 1.5 \mathrm{~mm}$ then deposited on a strip (Accu-Chek ${ }^{\circledR}$ Active). The determination of the glycemic responses $(\mathrm{g} / \mathrm{L})$ of coconut water sugars was performed by direct reading using a calibrated glucose meter (Accu-Chek ${ }^{\circledast}$ Active, GC, Mannheim Germany). The values obtained in $\mathrm{g} / \mathrm{L}$ were converted to $\mathrm{mmol} / \mathrm{L}$ by a factor $\mathrm{fc}=7 / 1.26$. The entire process of measuring the glycemic index is summarized from A to F (Figure 1).

\subsubsection{Calculation of the Glycemic Index}

The method of Bouns [10] was used to calculate the glycemic indexes of the various sugars studied. After obtaining the results, the curves of the glycemic 


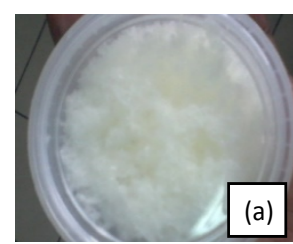

White coconut water sugar

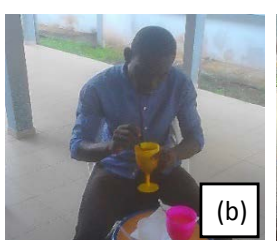

Homogeneization in water

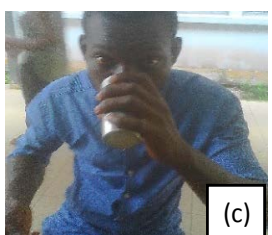

(c)

Consomption of sugar dissolve

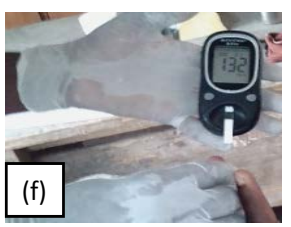

Glyceamiaresponse

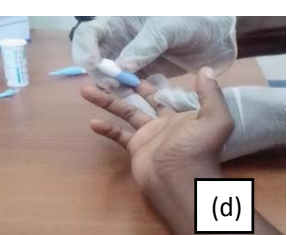

Take to capillaryblood

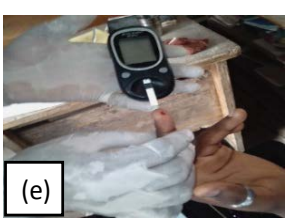

Blood drop on a read trip

Figure 1. Process to measuring of glycemic index of coconut water sugar.

responses (mmol/L) were plotted for each subject and per food consumed. The areas under the curves obtained were calculated by considering the part situated between the curve and the horizontal line passing through the glucose fasting and parallel to the axis of time. The trapezium method was used to exclude any area below the horizontal line of fasting blood glucose.

\section{Formula for calculating the glycemic index}

By observing the glycemic response curves obtained, the model for calculating the glycemic indices is illustrated in Figure 2.

\subsubsection{Statistical Analysis}

The SPSS software (IBM, SPSS Statistics 22) was used for statistical processing of the results obtained. ANOVA variance analysis was established by the Student Newman and Keuls (SN-K) test at the 5\% probability level. The Excel software has permitted the construction of the curves of postprandial glycemic responses.

\section{Results and Discussion}

\subsection{Results}

\subsubsection{Characteristics of People Who Participated in the Glycemic Index Test (Panelists)}

Table 2 presents the anthropometric and biological characteristics of the volunteers who participated to the study. It present also, their personal and family history if existed, decrypt theme and the results collected are recorded in the same table. The data show that all subjects met the inclusion criteria. In addition, $67 \%$ of the subjects selected to participate to the integrality of the test were male and aged between 22 and 39, with an average age of 27.8 years old. Also, they weight and height averages were $62.33 \mathrm{~kg}$ and $1.74 \mathrm{~m}$ respectively, they average of body mass index (BMI) was $20.59 \mathrm{~kg} / \mathrm{m}^{2}$ and the blood pressure averaged was 12.8/7.6 mmHg. No cases of obesity were found among the subjects. The subjects were characterized by a mean fasting capillary glucose level of $0.91 \mathrm{~g} / \mathrm{L}$ with values ranging from 0.75 to $0.98 \mathrm{~g} / \mathrm{L}$. 
Table 2. Characteristic of test panelists.

\begin{tabular}{|c|c|c|c|c|c|c|c|c|c|}
\hline \multirow{2}{*}{ Subjects } & \multirow{2}{*}{ Age (years) } & \multicolumn{2}{|c|}{ Sex } & \multirow{2}{*}{ Weight $(\mathrm{kg})$} & \multirow{2}{*}{ Height (m) } & \multirow{2}{*}{$\begin{array}{l}\text { Index body } \\
\text { mass }\end{array}$} & \multirow{2}{*}{ GAJ $(g / L)$} & \multicolumn{2}{|c|}{ Blood pressure $(\mathrm{mmHg})$} \\
\hline & & $\mathbf{M}$ & $\mathbf{F}$ & & & & & Systolic & Diastolic \\
\hline 1 & 22 & $x$ & & 59 & 1.75 & 19.26 & 0.92 & 12 & 8 \\
\hline 2 & 33 & & $x$ & 60 & 1.75 & 19.59 & 0.93 & 13 & 8 \\
\hline 3 & 23 & $x$ & & 63 & 1.78 & 19.88 & 0.89 & 13 & 8 \\
\hline 4 & 22 & $x$ & & 68 & 1.80 & 20.98 & 0.87 & 13 & 8 \\
\hline 5 & 25 & $x$ & & 66 & 1.72 & 22.30 & 0.98 & 12 & 8 \\
\hline 6 & 23 & $x$ & & 60 & 1.67 & 21.51 & 0.97 & 14 & 7 \\
\hline 7 & 32 & & $x$ & 59 & 1.66 & 21.41 & 0.97 & 12 & 7 \\
\hline 8 & 33 & & $x$ & 61 & 1.73 & 20.38 & 0.88 & 12 & 7 \\
\hline 9 & 39 & $x$ & & 70 & 1.82 & 21.13 & 0.91 & 13 & 7 \\
\hline 10 & 31 & & $x$ & 59 & 1.70 & 20.41 & 0.89 & 13 & 7 \\
\hline 11 & 20 & $x$ & & 67 & 1.86 & 19.36 & 0.88 & 12 & 8 \\
\hline 12 & 38 & $x$ & & 70 & 1.76 & 22.59 & 0.95 & 13 & 7 \\
\hline 13 & 23 & $x$ & & 62 & 1.70 & 21.45 & 0.82 & 13 & 8 \\
\hline 14 & 33 & $x$ & & 59 & 1.71 & 20.17 & 0.92 & 13 & 8 \\
\hline 15 & 20 & & $x$ & 52 & 1.68 & 18.42 & 0.86 & 14 & 8 \\
\hline Total & 417 & 12 & 3 & 935 & 26.09 & 308.84 & 13.64 & 192 & 114 \\
\hline Averages & 27.80 & $67 \%$ & $33 \%$ & 62.33 & 1.74 & 20.59 & 0.91 & 12.8 & 7.6 \\
\hline $\begin{array}{l}\text { Standard } \\
\text { deviation }\end{array}$ & 6.34 & 0.50 & 0.48 & 4.82 & 0.05 & 1.14 & 0.04 & 0.65 & 0.49 \\
\hline
\end{tabular}

M: Male, F: Female, GAJ: Glyceamia taken on an empty stomach (After 12 hours without eating).

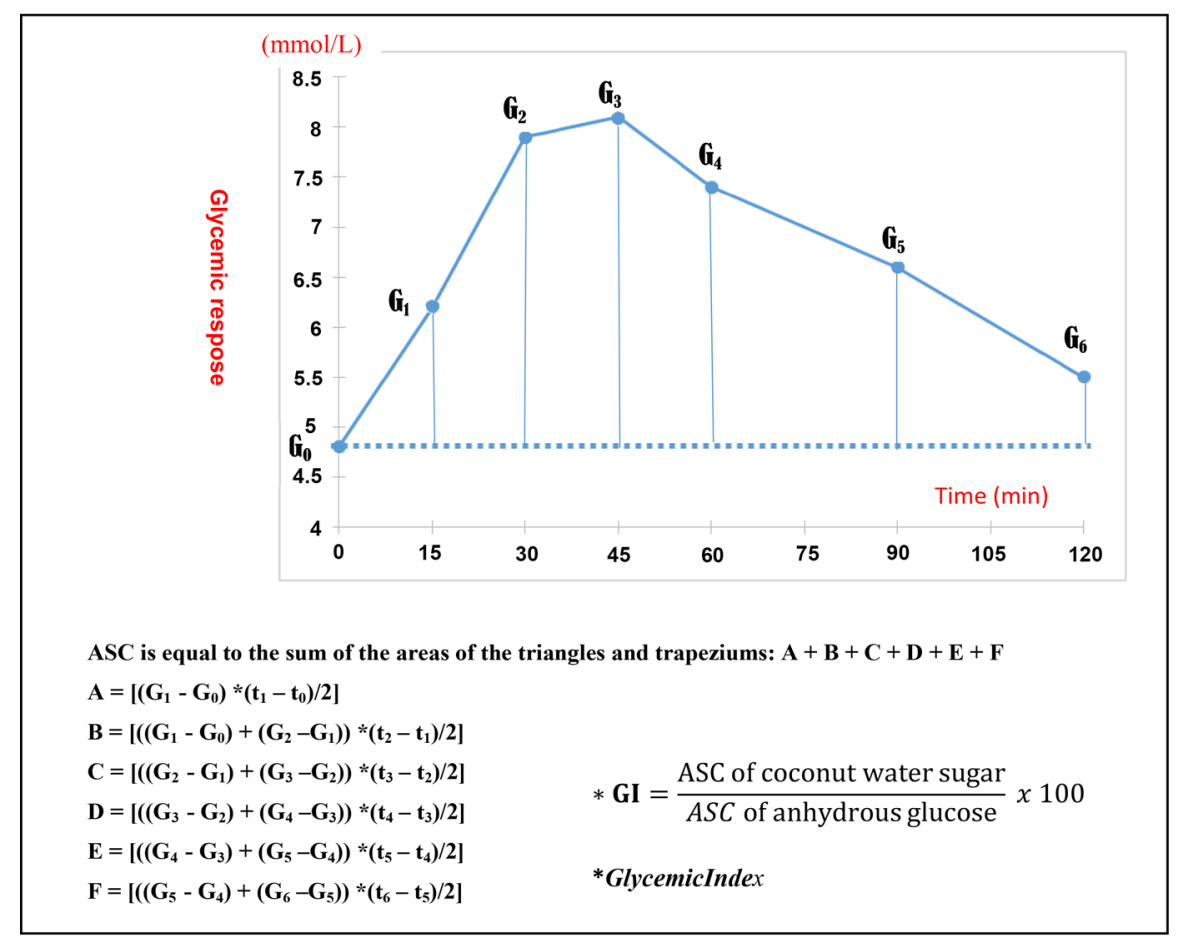

Figure 2. Illustraction to calcul of area under curve (ASC) of glycemic response. 


\subsubsection{Postprandial Glycaemia of Coconut Water Sugar}

The postprandial glycaemia levels of anhydrous glucose and sugars studied (brown sugar and white sugar varieties MYD, WAT and PB121 $1^{+}$) evolve similarly with two phases; a growth phase with a peak at $45 \mathrm{~min}$ with different glucose amplitudes. Then a phase of gradual decrease until a glucose value higher than this on the fasting blood glucose of the subjects after 120 minutes of the test.

These results in Figure 3, show a significant difference between the postprandial kinetics of the glucose levels induced by anhydrous glucose, the brown sugars and the white sugars from coconut water. After consumption of anhydrous glucose, the mean fasting glucose level of subjects at $4.8 \mathrm{mmol} / \mathrm{L}$ increased to an average value of $8.1 \mathrm{mmol} / \mathrm{L}$ after 45 minutes. In the first phase, anhydrous glucose produced the highest amplitudes increased by the highest peak $(8.1 \mathrm{mmol} / \mathrm{L})$ after 45 minutes.

After the anhydrous glucose (control), it is the brown sugars of the coconut water which have the highest amplitudes. As a result of their ingestions, the brown sugars induce an increase in blood glucose from $4.5 \pm 0.32$ to $7.3 \mathrm{mmol} / \mathrm{L}$ \pm 0.15 (MYD brown sugar), of $4.4 \pm 0,13$ to $6.6 \mathrm{mmol} / \mathrm{L} \pm 0.7$ (WAT brown sugar) and $4.6 \mathrm{mmol} / \mathrm{L} \pm 0.19$ up to $6.9 \mathrm{mmol} / \mathrm{L} \pm 0.35$ (brown sugar $\mathrm{PB} 121^{+}$). The lowest amplitudes of glycemic responses in this study were given by white sugars. Thus, after consumption, the subjects' fasting glucose level, which averaged $4.2 \mathrm{mmol} / \mathrm{L} \pm 0.08$, rose to $5.8 \mathrm{mmol} / \mathrm{L}$ for MYD white sugar after $45 \mathrm{mi}$ nutes. The white sugar of WAT resulted in a plasma concentration of $4.3 \mathrm{mmol} / \mathrm{L}$ \pm 0.77 which reached $6.1 \mathrm{mmol} / \mathrm{L} \pm 0.03$ (peak) 45 minutes after ingestion. Finally, the white sugar of hybrid $\mathrm{PB} 121^{+}$gave a glycemic response that increased from $4.2 \mathrm{mmol} / \mathrm{L} \pm 1.82$ on an empty stomach to $6.3 \mathrm{mmol} / \mathrm{L} \pm 0.15 \mathrm{af}-$ ter 45 minutes. During this growth phase, brown sugars gave statistically different peaks among the three varieties studied, while white sugars gave similar amplitudes between these varieties.
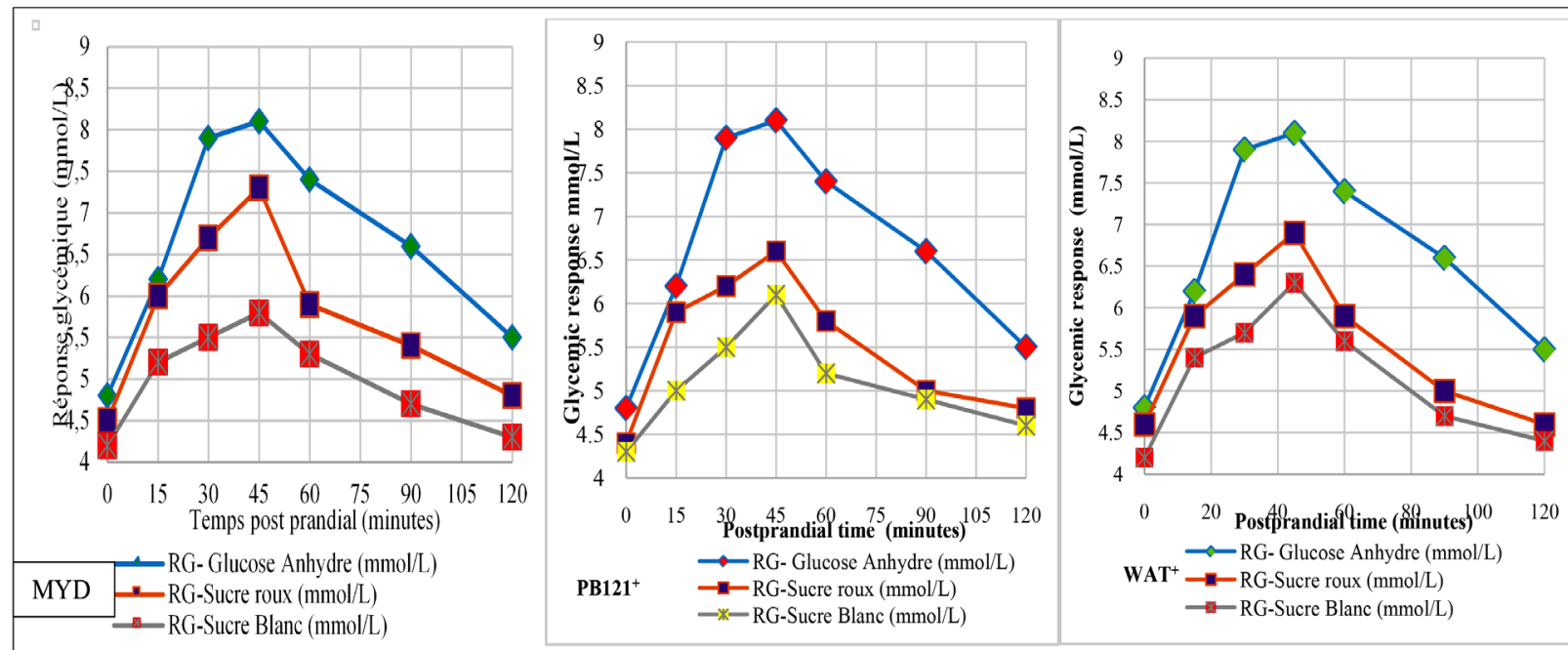

Figure 3. Glycemic responses of coconut water sugar from MYD, PB121 ${ }^{+}$and WAT. 
During the decreasing phase (45 to $120 \mathrm{~min}$ ), the glycemic responses decrease significantly resulting in a drop in blood glucose curves. Then, the kinetics of the postprandial glycemia of the subjects, induced by anhydrous glucose, decreased and reached an average of $5.5 \mathrm{mmol} / \mathrm{L} \pm 1.05$. Similarly, the glycemic responses of the brown sugars range from $7.3 \mathrm{mmol} / \mathrm{L} \pm 0.15$ to $4.8 \mathrm{mmol} / \mathrm{L} \pm$ 0.47 (NJM brown sugar), from $6.6 \mathrm{mmol} / \mathrm{L}$ to $4.8 \mathrm{mmol} / \mathrm{L}$ (WAT brown sugar) and $6.9 \mathrm{mmol} / \mathrm{L} \pm 0.35$ to $4.6 \mathrm{mmol} / \mathrm{L} \pm 0.45$ (brown sugar $\mathrm{PB} 121^{+}$). There is no significant difference between the final blood sugars of the brown sugars from the three varieties studied. Finally, white sugars move in the same direction with a regression ranging from $5.8 \mathrm{mmol} / \mathrm{L}$ to $4.3 \mathrm{mmol} / \mathrm{L} \pm 0.92$ for the white sugar of $\mathrm{NJM}, 6.1 \mathrm{mmol} / \mathrm{L} \pm 0.03$ at $4.6 \mathrm{mmol} / \mathrm{L} \pm 0.37$ for that of the WAT variety and $6.3 \mathrm{mmol} / \mathrm{L} \pm 0.5$ at $4.4 \mathrm{mmol} / \mathrm{L} \pm 0.75$ for the white sugar of the hybrid $\mathrm{PB} 121^{+}$.

There is a significant difference $(\mathrm{p}<0.05)$ between the magnitudes of the three sugars (anhydrous glucose, brown sugar and white sugar from coconut water) that were the subject of this study. The highest amplitudes were given by anhydrous glucose (control) followed by that of brown sugar and finally by those of white sugar. The amplitudes of the peaks of the brown sugars are higher in the MYD variety $(7.3 \mathrm{mmol} / \mathrm{L})$ followed by $\mathrm{PB}^{2} 1^{+}(6.9 \mathrm{mmol} / \mathrm{L})$ and finally WAT $(6.6 \mathrm{mmol} / \mathrm{L})$, all significantly different (Figure 3$)$.

\subsubsection{Glycemic Index of Brown and White Sugars in Coconut Water}

The interest of this chapter is to make a comparison of glycemic indexes of these sugars in order to use them correctly. This comparison is illustrated in Table 3. Apart glycemic index from the sugar of $\mathrm{PB} 121^{+}$(22.50\%), the white sugars of coconut water from MYD and WAT varieties have glycemic indexes less than or equal to that of fructose. White sugar from MYD and WAT yielded respectively $19.06 \%$ and $17.50 \%$ glycemic index. The glycemic indices are higher in the brown sugar than in the white sugar for the same variety. The glycemic index of sugars has risen, leading to a significant increase of $38 \%$ for the MYD, $46 \%$ for the WAT variety and $54.13 \%$ for the $\mathrm{PB} 121^{+}$. The brown sugar of the coconut palm NJM has the highest glycemic index at $50 \mathrm{mmol} / \mathrm{L}$, that of the variety WAT provided the lowest glycemic index $(37.81 \mathrm{mmol} / \mathrm{L})$ while the hybrid $\mathrm{PB} 121^{+}$ gave an intermediate glycemic index of $41.56 \mathrm{mmol} / \mathrm{L}$.

\subsection{Discussion}

The glycemic index classifies foods according to the elevation of blood glucose they produce when it is consumed.

After consumption of anhydrous glucose, brown and white sugars from coconut water, there was an increase in blood glucose in all subjects. This increase in blood sugar is due to the assimilation and digestion of sugars ingested. In addition, the sugars ingested are provided with monosaccharides, which causes a rapid rise in the blood glucose level.

Indeed, coconut water contains small amounts of sucrose [11] and is heated to obtain brown sugar which in turn contains a small amount (1.85\% to $5.38 \%)$. 
Table 3. Glycemic index of coconut water sugar.

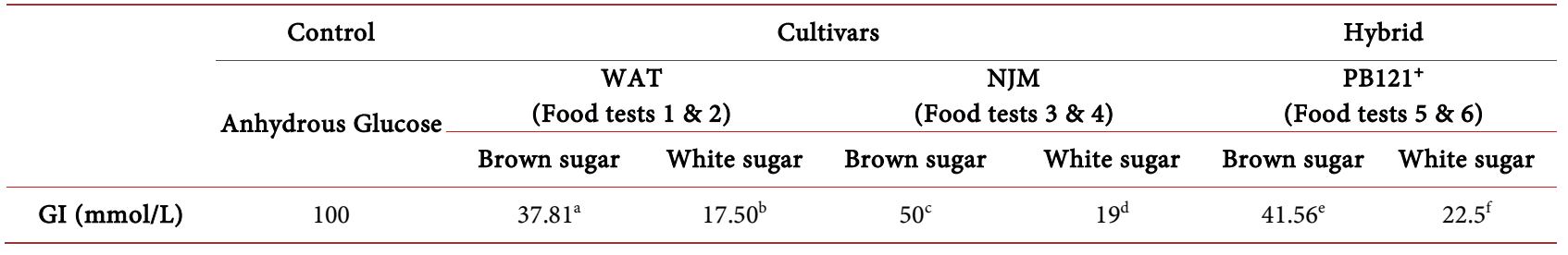

GI: Glycemic index. The letters a, b, c, d, e, f are different and mean that there is a statistically significant difference between the glycemic indexes of the sugars studied.

Schlinger [12] and Jenkins [13] have demonstrated this phenomenon through their numerous studies on the glycemic index. Thus, following the ingestion of sugars, several digestive enzymes including salivary alpha-amylase, pancreatic amylase, $\beta$-fructosidase, galactosidasewould hydrolyze sucrose and traces of starch into simple sugars. These are assimilated into the the small intestine, leading to a significant increase in blood glucose. These results are in agreement with those of Widmeyer [14].

The results also showed that the peaks of the glycemic responses of the sugars studied and the control (anhydrous glucose) all appear at 45 minutes after their consumption. Peak blood glucose levels observed with different magnitudes between red and white sugars may be justified by the fact that glycemic responses are related to the amount of hydrolysis products. The higher the amounts of hydrolysis products, the higher the blood glucose responses and the greater peak amplitudes.

With heat, brown sugars produce more hydrolysis products than white sugar with cold, and have a higher hyperglycaemic power.

Concerningthe glycemic index higher in red sugars than in white sugars, it could be explain by the fact that the hyperglycemic power of the brown sugar of the coconut water is also higher than that of white sugar.

This distinction could also be attributable to the intrinsic and extrinsic characteristics, or even to the nature of the sugars studied. Evaluation of the physicochemical characteristics of sugars, showed significant differences between macronutrient and micronutrient contents. This remark confirms the assertions of Pi-Sunyer [15], Bran-Miller [16], Mc-Clements [17] and David [18] who stiputate that postprandial glucose depends on the intrinsic and extrinsic characteristics, or even the nature of the food tested.

Also, this phenomenon has occurred because in gelatinized form, the hydrolysis of sucrose, despite being in small amounts, is accelerated by the amylases resulting in the production of monosaccharides.

Overall, the glycemic index of brown sugar is 2 to 3 times higher than that of white sugar for all the varieties studied. This discrimination is modulated by the heat treatment applied to obtain the brown sugar. Hydration and heat have had the effect of increasing the glycemic index. Indeed, according to Montignac [19] and Wolever [20], when the heating is prolonged, there is the phenomenon of 
gelatinization which is put in place and which causes the elevation of the glycemic index of the food.

The progressive regression of plasma glucose level that occurred between 45 and 120 minutes after consumption of sugars is justified by the establishment of a system for restoring carbohydrate homeostasis. The accumulation of monosaccharides in the blood stimulates the pancreas, which secretes insulin to transport sugars into muscles and adipocytes. Indeed, the $\beta$-pancreatic cells secreted insulin which facilitated or increased the uptake of sugars consumed by the appropriate cells in the muscles, liver and adipocytes that will use them for the metabolism of the body. This justification is supported by the results of Ingels [21] following her work on the notion of glycemic index. It is this phenomenon that has led to a gradual decline in the level of plasma glucose and which eventually stabilizes. The blood glucose level drops more slowly for white sugar than for brown sugar. This stabilization is caused by the secretion of counter-regulatory hormones such as glucagon, epinephrine and cortisol. The latter acts in an antagonistic way to insulin to allow the body to regain euglycemia. Moreover, they induce a better sensitivity to insulin which can also induce an improvement in thrombosis factors and endothelial functions as justified.

\section{Conclusion}

The objective of this study was to determine the sugar glycemic index of coconut water from immature coconuts. These sugars would be advisable in dietary prescriptions of people at risk for diabetes. It should be remembered that the sugars ordinarily consumed are lacking in nutrients and are only empty calories. The results of this study showed that brown and white sugars in coconut water are classified as low glycemic index foods. Nevertheless, white sugars have a glycemic index 2 to 3 times lower than that of brown sugars. Thus, consumption of white sugar from coconut water may be recommended to people with diabetes who normally have to pay attention to sucrose. In addition, both categories of sugar would be suitable for consumption by healthy people at risk of diabetes. Also, the glycemic indexes of sugars vary according to the variety of coconut used. The sugars of the coconut palm (MYD) are more hyperglycemic than those of the hybrid $\left(\mathrm{PB} 21^{+}\right)$which is more hyperglycemic than the sugars of the coconut palm (WAT). Thus, with a controlled consumption, the sugars of the water of the immature nuts of coconut tree could be the sugars that are best for the health of the healthy and diabetic populations because it raises slightly the postprandial glucose.

\section{Conflicts of Interest}

The authors declare no conflicts of interest regarding the publication of this paper.

\section{References}

[1] Pamplona-Roger, G.D. (2011) Guide des aliments et leur pouvoir curatif. Bibliothèque 
Education et Santé, 1, 159-179.

[2] Brownlee, M. (2005) The Pathobiology of Diabetic Complications: A Unifying Mechanism. Diabetes, 54, 1615-1625. https://doi.org/10.2337/diabetes.54.6.1615

[3] Malmberg, K., Ryden, L., Wedel, H., Birkeland, K., Bootsmaa, A., Dickstein, K., Efendic, S., Fisher, M., Hamsten, A., Herlitz, J., Hildebrandt, P., Macleod, K., Laakso, M., Torp-Pedersen, C. and Waldenstrom, A. (2005) Intense Metabolic Control by Means of Insulin in Patients with Diabetes Mellitus and Acute Myocardial Infarction (DIGAMI 2): Effects on Mortality and Morbidity. European Heart Journal, 26, 650-661. https://doi.org/10.1093/eurheartj/ehi199

[4] Valensi, E. (2006) Physiopathologie des complications du diabète. Dossier Cour du diabète, 5 .

[5] IDF (2007) Diabetes Atlas Style de Vie-Alimentation Saine. Medical Support, International Diabetes Foundation, 3.

[6] Rizkalla, S.W., Bellisle, F. and Slama, G. (2002) Health Benefits of Low Glycaemic Index Foods, Such as Pulses, in Diabetic Patients and Healthy Individuals. British Journal of Nutrition, 88, 255-262. https://doi.org/10.1079/BJN2002715

[7] Anselme, L.A., Jean-Louis, K.K., Albarin, G.G., Roger, B.K. and Didier, Y.S. (2018) Physicochemical Coconut Water Assessment and of the Microbiological Quality of Its Sugar Extracted of Five Coconuts Ecotypes at the Marc Delorme Station, Côte d'Ivoire. International Journal of Applied Biology and Pharmaceutical Technology, 1, 24-31.

[8] Chan, H.M., Brand-Miller, J.C. and Holt, S.H. (2005) The Glycaemic Index Values of Vietnamese Foods. European Journal of Clinical Nutrition, 55, 1076-1083.

[9] FAO/WHO (1998) Expert Consultation. Carbohydrates in Human Nutrition. FAO Food and Nutrition Paper, Report of a Joint FAO/WHO Expert Consultations, Food and Agriculture Organization, Rome, 66.

[10] Brouns, F., Bjorck, I. and Frayn, K.N. (2005) Glycaemic Index Methodology. Nutrition Research Reviews, 18, 145-171. https://doi.org/10.1079/NRR2005100

[11] Assa, R.R., Konan, J.L., Agbo, N., and Nemlin, J. (2007) Caractérisation physicochimiques de l'eau des fruits de quatre cultivars de cocotier (Cocos nucifera L.) en Côte d'Ivoire. Agronomie Africaine, 19, 41-51.

[12] Schlienger, J.-L. (2013) Sucre et "faux-sucres": Leur place dans l'alimentation du diabétique. Insulib, 16, $29 \mathrm{p}$.

[13] Jenkins, D., Wolever, T. and Taylor, H. (1981) Glycemic Index of Foods: A Physiological Basis for Carbohydrate Exchange. American Journal of Clinical Nutrition, 34, 362-366. https://doi.org/10.1093/ajcn/34.3.362

[14] Wiedmeyer, C.E., Johnson, P.J., Cohn, L.A. and Meadows, R.L. (2011) Evaluation of a Continuous Glucose Monitoring System for Use in Dogs, Cats, and Horses. Journal of American Veterinary Medical Association, 223, 987-992. https://doi.org/10.2460/javma.2003.223.987

[15] Pi-Sunyer, F. (2002) Glycemic Index and Disease. American Journal of Clinical Nutrition, 76, 290S-298S. https://doi.org/10.1093/ajcn/76.1.290S

[16] Brand Miller, J.C., Gilbertson, H.R., Thorburn, A.W., Chondros, P. and Werther, G.A. (2003) Effect of Low Glycemic Index Dietary Advice on Dietary Quality and Food Choice in Children with Type 1 Diabetes. American Journal of Clinical Nutrition, 77, 83-90. https://doi.org/10.1093/ajcn/77.1.83

[17] Mc-Cléments, D.J. and Decker, E.A. (2009) Controlling Lipid Bioavailability Using Emulsion-Based Delivery Systems. In: Designing Functional Foods: Measuring and 
Controlling Food Structure, Breakdown and Nutrient Absorption, Woodhead Publishing Limited, Cambridge, CRC Press, Boca Raton, 502-546. https://doi.org/10.1533/9781845696603.3.502

[18] David, A.B. and Peter, A.M. (2017) Gluconéogenèse et contrôle de la glycémie. In: Bender, Botham, Kennelly, Rodwell and Weil, Eds., Biochmie de Harper, De Boeck Supérieur, $156 \mathrm{p}$.

[19] Montignac, M. (2011) Facteurs influençant l'index glycémique d'un aliment. http://www.montignac.com/fr/index-glycemique

[20] Wolever, T.M.S., Vorster, H.H., Bjorck, I., Brand Miller, J., Brighenti, F., Mann, J.I., Ramdath, D.D., Granfeldt, Y., Holt, S., Perry, T.L., Venter, C. and Wu, X.M. (2003) Determination of the Glycemic Index of Foods: Interlaboratory Study. European Journal of Clinical Nutrition, 57, 475-482. https://doi.org/10.1038/sj.ejcn.1601551

[21] Ingels, C., Vanhorebeek, I., Langouche, L. and Van den Berghe, G. (2006) Role of Insulin and Blood Glucose Control to Improve Outcome of Critical Illness. Réanimation, 15, 474-480. https://doi.org/10.1016/j.reaurg.2006.09.007 